\title{
XXVII. Process employed to obtain a black liquid, invented by Mr. Clarke, an englishman, and introduced into commerce; its use in marking linen in a solid and durable manner, and its application for printing cottons or stuffs
}

\section{Hermbstadt}

To cite this article: M. Hermbstadt (1806) XXVII. Process employed to obtain a black liquid, invented by Mr. Clarke, an englishman, and introduced into commerce; its use in marking linen in a solid and durable manner, and its application for printing cottons or stuffs , Philosophical Magazine, 24:94, 165-167, DOI: $10.1080 / 14786440608563353$

To link to this article: http://dx.doi.org/10.1080/14786440608563353

曲 Published online: 18 May 2009.

Submit your article to this journal 주

Џll Article views: 2

Q View related articles ¿ 
XXVII. Process employed to obtain a Black Liquid, invented by Mr. Clanke, an Englishman, and introduced into Commerce ; its Use in marking Linen in a solid and duralle Manner, and its Application for printing Cottons or Stuffs. By M. Henmbst 1 di, of Berlin.

$F_{\text {OR these two or three years past, a black tincture has been }}$ sold for the purpose of marking linen.

A glass polisher and directions for using the tincture accompany the two bottles which contain the ingredients, and the whole is sealed up in a case.

One of the bottles contains the mordant. The other contains the ink, which is of a deep brown colour, and which must be well shaken before making use of it, because it subsides when left to rest.

The part of the linen intended to be marked must be in the first place impregnated with the mordant, which is allowed to dry on the linen. The place which had been wetted is then rubbed with the polisher; an ordinary pen is then dipped in the ink, and the writing is performed on the linen the same as on paper. Neither soap nor any chemsical preparation will destroy this writing, which, when well dried, is of a very fine black.

Having chemically analysed these two liquids, I am able to give an account of the ingredients which compose them.

Preparation of the Ink.

Dissolve in nitric aeid (aquafortis) what quantity of silver you please. This solution, if the silver has been alloyed with copper, will be of a sapphire blue.

In order to separate the copper from the silver add to the solution twelve times its weight of distilled water, or, for want of it, rain water, and suspend in it a thin plate of copper. In proportion as this plate dissolves, the silver will precipitate itself, perfectly pure, in the form of a white powder. When no more of this powder will precipitate itself, the liquor should be decanted. The powder is then washed in a great quantity of water, until the water thrown upon it 
is no longer of a blue cast, but remains perfectly limpid. The residue, i.e. this powder, well dried, will be silver in its purest state.

If this residue weighs one ounce, dissolve as much gum senegal and two drachms of white glue in two ounces of distilled water. Mix this solution with three drachms of lamp-black well calcined in a close crucible.

To manufacture this mixture properly, it ought to be triturated in a grlass mortar.

This operation being finished, the solution of silver, diluted in eight times its weight of distilled water, is poured upon the above mixture: the whole is then well stirred with a spatula, and the ink is made.

\section{Preparation of the Mordant.}

Dissolve two ounces of white glue and as much isinglass, in six ounces of alcohol and as much distilled water. This solution will be made in two days. The B. M. is made use of for the purpose; and care must be taken to stir the two kinds of glue from time to time,

After the whole is dissolved, it must be filtered through flannel, in order to keep back all its mucilaginous particles. The liquid thus filtered, and preserved in a bottle well corked, is then ready for use.

\section{Mamer in which the Ink acts.}

The solution of silver in the nitric acid is nothing else than the composition of the lapis infernalis; and every one knows its properties in staining the skin, nails, \&xc., of a black colour. If the linen or stuff is first impregnated with the above mordant, which is an animal substance, the ink may be afterwards applied without spreading, and will completcly dye every thread of the part to which it is applied, the mordant having previously partly animalized the fibre of the fabrie.

Soap, or any other ingredient used in washing, may obliterate the lamp black, but it never takes. out the nitrate of silver; and the object proposed is therefore perfectly well attained. 
Application of the Ink for printing orange Cotton and other Stuffs.

We may easily conceive that this ink may be employed with advantage for printing cloths of a white, yellow, or rose ground, or any other clear colour.

The cloths or stuffs intended to be printed in this manner; require no other preparation than to be dipped in a solution of parchment or isinglass; and after they are dried they must be rubbed with a glass polisher.

The ink must be thickened for this purpose with a grester quantity of gum senegal, and then applied upon the cloths or stuffs in the usual manner by means of wooden or metal stamps.

Three or four days after this operation the stuffs must be first washed with a great quantity of clear water, and afterwards with soap and water, which will make them appear of 2 finer black.

XXVIII. Letter of Messrs. Civni and Petrini to Professor Pacchiani, of Pisa, on the supposed Production of Muriatic Acid by Galvanism*.

W positive pole of the electrical column under water, obtained oxygen gas and an acid as the result of his analysis; and when he recognised in this acid all the characteristics of the muriatic acid, he supposed that it might be produced by the muscular fibre which he had substituted in the place of the metal wire communicating with the negative pole of the column; and he went no further than imagining that he had only obtained a result new, interesting, and agreeing extremely well with the most luminous facts of pneumatic chemistry.

It was reserved for you to trace this result a little further; and your repetition of the experiment produced this new and

* Abridged from Annales de Chimie, tome lvi. p. R69.

† Annales de Chinie, tome xli. p. 106.

I. 4 important 